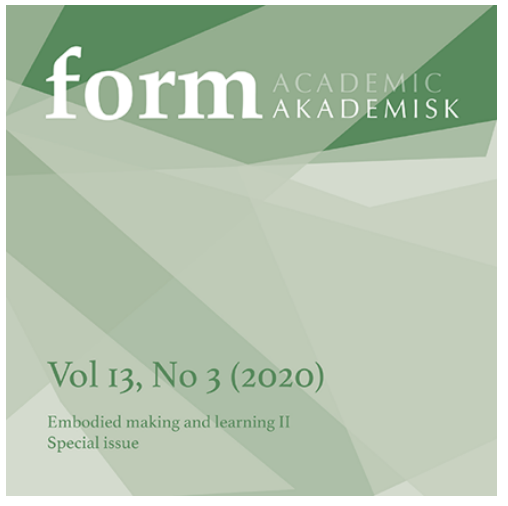

https://doi.org/10.7577/formakademisk.3549

Biljana C. Fredriksen

Associate Professor, PhD,

University of South-Eastern Norway, Faculty of Humanities, Sports, and Eductonal Science

Biljana.C.Fredriksen@usn.no

\title{
More-than-human perspectives in understanding embodied learning
}

\author{
Experience, ecological sustainability and education
}

\begin{abstract}
The abilities to learn through embodied interactions with environments are biologically imprinted in humans and other species in order to preserve their survival. By combining data from studies on the experiential learn of young children and a foal (a new-born horse), this article shows how more-thanhumans learn through self-initiated actions, embodied intra-action with their environments and considerate choices of action. The article suggests that a justification of embodied learning as crucial for survival across species could motivate the deconstruction of dualisms between embodied and verbal, and between humans and other-than-humans, promoting a more holistic understanding of learning. In times of emerging ecological challenges, embodied forms of learning can cultivate ecological awareness and provide the conditions for education for ecological sustainability.
\end{abstract}

Keywords:

more-than-human, embodiment, experience, multispecies ethnography, ecological sustainability

\section{INTRODUCTION}

The education system plays such a central role in contemporary cultures that we sometimes find it difficult to imagine how we would be able to learn without it. Nevertheless, as living beings with sensual and active bodies, humans are similar to other species; we are able to learn from experiences outside the classroom, beyond verbal transmission of knowledge and disregarding cultural expectations. Entangled in our cultures as spiders in their webs (Geertz, 1993), we sometimes fail to see the obvious until something surprising shakes us off balance - out of our webs. Through unconventional examples of embodied learning that are independent of both verbal language and teaching, this article shows that embodied learning is a capacity that is present not only in humans, but also in other animal species: in 
more-than-humans. Embodied learning through direct contact with our environment is deeply grounded in our genetic make-up; it so essential that it maintains the survival of the species (Gibson, 1979). Consciousness is fundamentally corporeal and dependent on action (Sheets-Johnstone, 2011). "Cognition is a very broad term for activities of neurons participating in thinking, motivation, emotion, perception, motor planning, and executive functions, such as when making deliberate choices of actions" (Gulliksen, 2016, p. 6).

The complex and intricate forms of living together in groups - which we also call culture render humans more robust, but also more vulnerable and less able to survive without the protection of our societies. While humans have been learning from each other and relying on education, if education fails to teach us how to learn from embodied interactions with our environment on an individual level, we will be less able to meet environmental challenges. In a time of rapid changes of climate and ecosystems, it is necessary to constantly question which kinds of competence and knowledge new generations need. We must also change in order to adapt in accordance with the changing affordances of our environments (Gibson, 1979).

This article presents embodied learning in a holistic manner and from a post-humanist ontological position in which anthropocentric views are questioned and dichotomies between humans and nonhumans are deconstructed. Confronting taken-for-granted assumptions about human uniqueness offers the possibilities to learn about ourselves by studying other animals (Bradshaw, 2010). We can apply animal models in order to understand human conditions (Shapiro \& DeMello, 2010). This article refers to two studies that aimed to provide an in-depth understanding of embodied, experiential learning. The first study focused on young children's experiential learning, while the other focused on a new-born foal's experiential learning. The question this article seeks to answer is: How can a study of more-than-human intra-actions with natural materials facilitate an understanding of embodied learning as shared among species and fundamental for survival?

From a position of an Arts \& Crafts teacher in early childhood teacher education, and a researcher with a special interest in the relationship between active bodies and three-dimensional materials, I understand learning as a process of negotiation of meaning through action (Fredriksen, 2011a) and intra-action (Barad, 2007; Lenz Taguchi et al., 2010). Action is important for learning because it is the self-movement of an organism that "structures knowledge of the world", "is fundamental to lives of animate forms" and "is at the root of (our) sense of agency" (Sheets-Johnstone, 2011, p. xx). Intra-action exceeds interaction by acknowledging more-than-human agency; in the process of gaining new understanding, novel insights are negotiated through complex intra-actions between all of the participants: objects, materials, humans and non-humans.

In education, the arts generally have a more practical, experiential and holistic approach to learning than theoretical subjects. In the arts, emphasis is given to individual uniqueness, emotions, senses, imagination and creativity (Eisner, 2002). This article expresses the urgency of taking embodied learning seriously in schools and across school subjects. To understand my reasoning regarding morethan-human embodied learning, it is important to accept that the real world (beyond schools) is interdisciplinary, complex and in motion. Acknowledging the connectedness between an individual and her/his physical, social and ecological others is the first step toward applying a holistic view to understand the concept of learning. In turn, facilitating possibilities for a holistic understanding demands that we try to resist the dualisms and hierarchies that exist in human cultures.

\section{THEORETICAL BACKGROUND}

\section{Contemporary ecological contexts and the holistic understanding of learning}

In the early part of the $20^{\text {th }}$ century, Dewey (1916) wrote that the self is never ready-made; it is in continual transformation. This echoes the more contemporary concepts of human becomings (Haraway, 2003) and biosocial becomings (Ingold \& Palsson, 2013). We (humans) are in a constant process of transformation; however, in order to attune to the extent of transformation in our natural environment, we need to speed up (Konst, 2019) and extend the scope of our own process of biosocial becoming. 
Education has the power to reach out to young people and facilitate the conditions for their personal transformations. To grasp how important human actions are for the planet, each individual needs to experience connectedness to the environment and to take responsibility for his/her own actions. "Recognition of and engagement with more-than-humans as agential and communicative beings is at the core of a transformative sustainability learning" (Barrett et al., 2017, p. 132). However, to facilitate such transformative processes, education needs to be reorganised (Raus \& Falkenberg, 2014) so as to embrace a more holistic understanding. I suggest that the term holistic can be understood in terms of five different spheres (Fredriksen, 2019a):

1. The personal sphere: Connectedness within a person, including emotions, imagination, senses, physical body, values, attitudes, memories, past experiences, physical needs, cognitive capacities, anomalies, illness, age, moods, talents, interests, etc.

2. The familiar social sphere: Connectedness between a person and her/his social environments, family, local culture, school, etc.

3. The reachable sphere: Connectedness with the surroundings that one is in immediate contact with: air, ground, clothes, food, objects, buildings, furniture, materials, smells, sound, etc.

4. The inter-species sphere: Connectedness with other species that one is in contact with, though one might not be aware of such contact: plants, wild and domestic animals, insects, microorganisms, etc.

5. The global sphere: Connectedness with more-than-humans we have never met, those that lived before and will live after us, who live in distant places we have never been to or places we do not even know about. This includes living organisms and materials that each of us influences at the global level since we share air, water, exhaust, micro plastic, viruses, the sun and many other elements.

Brundtland's definition of sustainable development from 1987 called for ways of living that do not destroy life possibilities for new generations (United Nations, 2013). Much has happened since 1987, and we are now more aware that it is not enough to only consider new generations of humans; we must also include other species. A transition to a more holistic understanding of ourselves as a part of the world demands an inter-disciplinary approach in education (Sinnes \& Straume, 2017). All five of the previously-mentioned spheres should be concerns of education. Yet, contemporary educational trends towards measurements and competition reinforce the dualisms embedded in our cultures. Such dualisms prevent a holistic understanding of ourselves in our environments. Consequently, they also justify and maintain the established power unbalance between species (Finley, 2012). To understand embodied learning, one has to accept the complexity of the connectedness between an individual and the world. While embodied learning is interdisciplinary, the organisation of academic disciplines is not (Fox, 2008). Fox (2008) called for better articulation of the relationship between experiential learning and other disciplines.

\section{Embodied learning}

Body, mind and environment are inextricably connected (Howes, 2005). To survive, all organisms have to learn through their bodies and in relation to the affordances of their environment (Gibson, 1979). "The organism that is unable to adapt to external change perishes" (Sterling, 2011, p. 18).

Understanding both embodied learning and experiential learning presupposes acknowledging the complexity of learning, as described above. Experiences consist of emotional, practical and cognitive dimensions (Dewey, 2005 [1934]), and experiential/embodied learning is simultaneously individual, social and biological (Seaman, 2008). It is a complex process, not linear or sequential (Seaman, 2008). Learning depends on perception and "perception is a combination of all modalities forming an embodied understanding of the world" (Groth et al., 2013, p. 3). Particularly because of this complexity, it is difficult to separate the concepts embodied and experiential. Eisner $(2002$, p. 1) emphasised the connections between the individual, social and cultural sides of an experience: "Experiencing the environment (...) is a process that is shaped by culture, influenced by language, impacted by beliefs, affected by values, and moderated by distinctive features of ourselves that we sometimes describe as our individuality". On an individual level, experiencing environments is very personal, because every being is physically separated from others, and her/his sensations are embodied-they are somaesthetic 
(Shusterman, 2008); thus, they can, to some degree, be shared verbally. Experiences are rich, and when young children try to verbalise them, they have to compress the experiences and simplify them in order to fit them into the few words and categories they are capable of using (Fredriksen, 2011a). "Before language sets in (...) we perceive a world abounding in quality and we sense ourselves moving in qualitative ways" (Sheets-Johnston, 2011, pp. 105-106). Due to the traditional hierarchy of the five senses, the tactile sense seems to be subordinated to visual and audio (verbal) senses (Groth et al., 2013); however, it is through the sense of touch (with all parts of our bodies) that we communicate with our surroundings in the most intimate ways (Steinslie, 2010). Embodied ways of knowing are mistakenly and unfairly repressed by verbal forms of knowing (Ingold, 2013b). Once one way of knowing has been established as the dominant discourse, it becomes normative for all production of knowledge (Braidotti, 2002). Referring to Stern's (1998) research with young children, Sheets-Johnstone (2011, p. 436) noted:

When the definitive shift into language takes place, that is, when thinking in words comes to dominate thinking in movement, a foundationally rich and subtle mode of thinking is displaced and typically subdued, commonly to the point that it is no longer even recognized as a mode of thinking.

The focus on verbal forms of learning is reinforced by neo-liberal trends in education that seek uniformity and efficiency of knowledge production (Robinson, 2016). Thus, when business models are applied to education, even "experience becomes something technical and instrumental" (Roberts, 2008, p. 29).

If we consider that early life experiences are so fundamental that they are carried "into the very fabric of our cognition" (Thelen \& Smith, 1994, p. 326), then it is easy to understand Villemain's (1966) claim that embodied experience and qualitative thinking are the most essential forms of thinking without which no other thinking would be possible. It is through an active process of self-discovery that "one can really know things (...) from the very inside of one's being" (Ingold, 2013b, p. 1). Such an active process demands an inner will to act upon the environments into which each of us is born (MerleauPonty, 1962). Together with attention, sensibilities, emotional engagement, inter-subjectivity, imagination and the ability to make sense of one's own experience, the will to act has been described as one of the embodied capacities", biologically imprinted in our genetic make-up in order to secure survival (Fredriksen, 2011a). The inner will is the driving force behind self-discovery (Sheets-Johnston, 2011). Motion is the foundation for meaning (Sheets-Johnston, 2011).

Our past experiences are always with us, and they influence our further understanding of ourselves and the world. The junction between new and old experiences leads to the re-creation of understanding; experiences from the past are "literally revived, given new life and soul through having to meet a new situation" (Dewey, 2005 [1934], p. 63). Sometimes, these new understandings take the form of micro-discoveries, which are elucidating moments when personal connections between past and present experiences are established (Fredriksen, 2011a). While micro-discoveries are small accomplishments, they are important for the person who achieves them. They lead to the experience of mastery, motivate further explorations and nourish the inner will to act (Fredriksen, 2011b). Because learning - and the process of human becoming-is full of risk and unpredictability (Biesta, 2013), the will to act has to be nourished and supported throughout life so it does not crumble under pressure and disappear with the first disappointment.

Genuine learning comes from experience (Dewey, 2007 [1938]), demands true connectedness, dwelling, exploring, time and emotional engagement, and is everything but efficient or instrumental. While the experiences of adults are mediated by verbal language and, therefore, are less authentic (Roberts, 2008), studies on the experiences of young humans and more-than-humans can expand the view that silent processes are hidden within active, sensing and thinking bodies. "In vertebrate species, early learning is largely nonverbal, unconscious and implicit" (Bradshaw, 2010, p. 413). It is through grappling to understand the world around us, through our embodied interactions, that we learn to become a part of the world (Haraway, 2003); this is not accomplished through generalised descriptions. Constantly changing circumstances challenge us to keep grappling and dealing with the world in motion. 


\section{More-than-human perspectives}

Animals are defined as other-than-human; however, humans have much more in common with other animals than we care to admit (Shapiro \& DeMello, 2010). We even share more than 50\% of our DNA with bacteria (Foros \& Vetlesen, 2015), and we are not the only species with skills for nuanced communication, reasoning and symbolic imagination (Ingold, 2011). Humans and other primates share many emotions, and they have approximately the same behavioural repertoire (De Waal, 2019). Similarities between humans and other species are evident in recent neuroscience discoveries of mirror neurons and oxytocin-a hormone that allows us to connect emotionally when we touch (Shapiro \& DeMello, 2010). Emerging interdisciplinary research that crosses the boundaries between biology, psychology and anthropology, requires us to rethink what humanity means when humans can no longer be understood as disconnected from other species (Ingold, 2013a).

There has been a significant increase in interest in studies on human-animal relations, especially in cross-disciplinary research (Davis \& Maurstad, 2016). Many recent studies have criticised anthropocentrism in academia and the arrogance toward other species based on the assumption of human exceptionalism (Braidotti, 2013). Growing criticism of human domination in the equine world, for instance, has led to greater interest in equine perceptions and horses' ways of learning (De Georgio \& De Georgio-Schoorl, 2016). Among new research fields, zooanthropology is a field that includes several scientific, philosophical and political disciplines where other-than-human animals are viewed from non-anthropocentric perspectives. Recognising animal subjectivity and alterity ("otherness") further "opens up a new model of interpretation and application in the dynamics of animal learning" (De Georgio \& De Georgio-Schoorl, 2016, p. 16). Similarly, innovative movements in biosocial anthropology (Ingold \& Palsson, 2013) suggest ways of understanding more-than-human animals as individual, biological and social beings.

Assumptions about human predominance have led to the exaggeration of differences between humans and other animals, and ignorance of the similarities between them. In many cultures, comparing a human with an animal is considered to be an insult. Similarly, assigning human characteristics to animals (also called anthropomorphism) has been considered to be romantic, ridiculous or at least non-scientific. In fact, the notion of anthropomorphism has contributed to the maintenance of human power and reinforced the exclusion between humans and other species (Rautio, 2017).

Other animals are our "companion species not only through recent history but through our evolutionary history" (Shapiro \& DeMello, 2010, p. 312). For example, the socio-emotional lives of chimpanzees "resemble ours to such a degree that it is unclear where to draw the line" (De Waal, 2019, p.19). Biological predispositions for embodied learning are shared among more-than-human species. Both humans and other mammals have to learn through interactions with their surroundings. Both humans and other species have sensing bodies that make embodied learning, inter-subjectivity and empathy possible (Roberts, 2008). Based on his study with an elephant, Locke (2017, p. 360) noted: "Our intimate interactions revealed to me personal recognition, intentionality, playfulness, attentive concern, and an ability to convey preferences and desires. As I would learn, these are constituents of what animal behavioural scientists identify as empathic consciousness". Such similarities across species make it possible to intuitively grasp the emotions in an individual that belong to a species that is different than one's own (De Waal, 2019).

The lives of humans and other animals depend on emotions because emotions are evolution's way of encouraging behaviours that promote survival (Keim, 2017). "Emotions evolved (...) for their capacity to induce adaptive reactions to danger, competition, mating opportunities, and so on. Emotions are action-prone" (De Waal, 2019, p. 20). In times of environmental changes, the life of morethan-humans depends on intact senses and emotional responses, as well as on metacognition, which is "an evolutionary useful way of reacting to uncertainty and changing conditions" (Keim, 2017, p. 31). The assumptions of human predominance have made it illegitimate to apply an understanding of animal learning in order to understand human learning. I suggest that we have much to learn from animals, but since every being is a distinct individual, only specific individuals have the capacity to teach us about 
experiential learning. In our societies, both humans and horses have been trained to forget how to experience:

...due to their coexistence with humans, horses gradually change because not only do they usually grow up in context in which the elements that make a socio-cognitive environment have vanished, but they also start to fulfil a human purpose. (De Georgio \& De Georgio-Schoorl, 2016, p. 12)

Here, "human purpose" means being obedient, not thinking and simply following human instructions. Some horses become numb when they are, time after time, punished for their attempts to communicate, or when they show curiosity and creativity. Consequently, I suggest that a new-born foal, the daughter of a rebellious horse that had earlier resisted human "contamination" (Fredriksen, 2016b), made a suitable subject for my study of embodied learning.

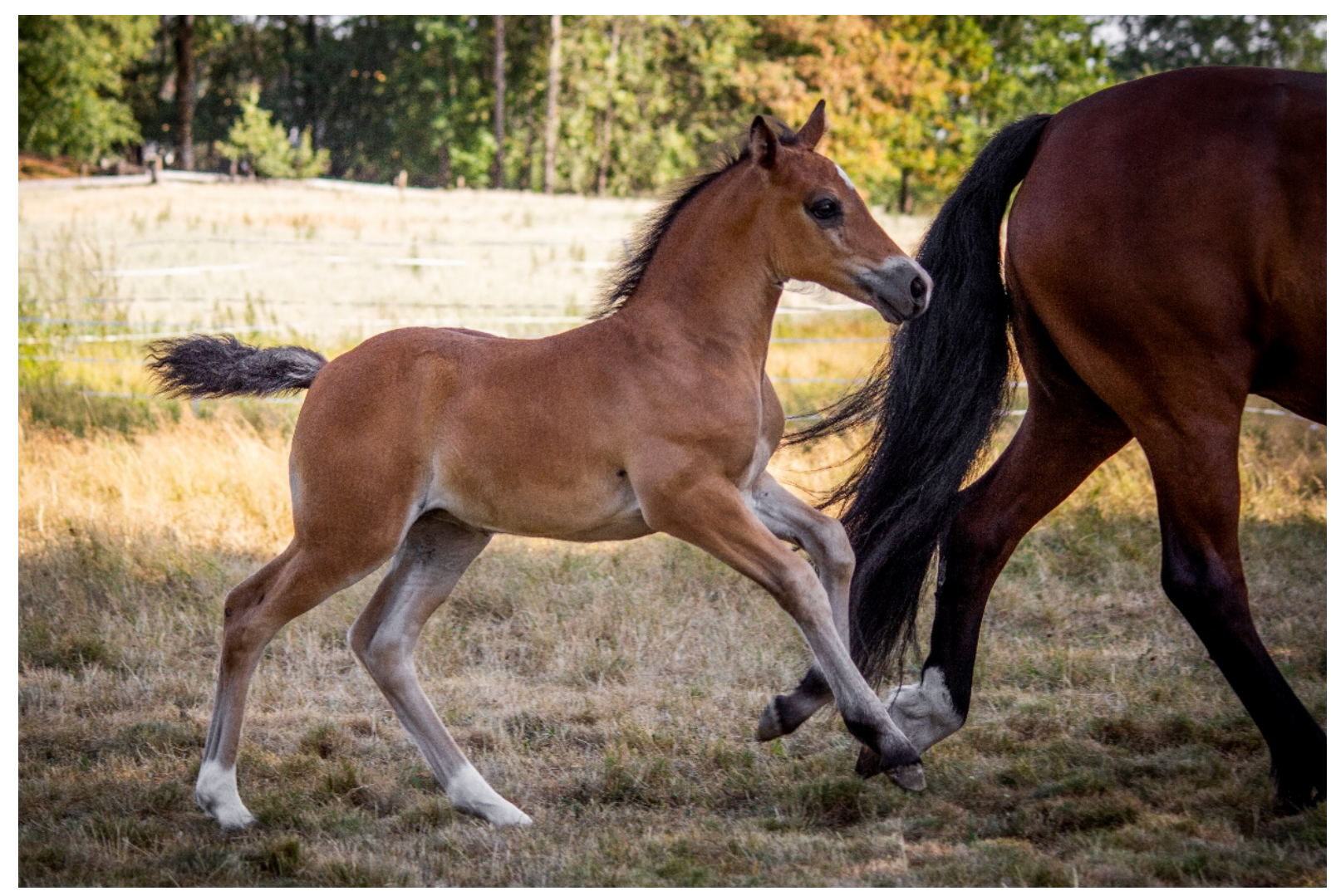

FIGURE 1. Foals are able to walk and run shortly after their birth. The photo shows one-month-old Zafirah in motion with her mother (photo credit: FotoVrolijk).

The following critique of equine training resonates well with my understanding of human education: "By focusing on (...) results, we also slowly and often unknowingly train ourselves to ignore" the real value of experience (De Georgio \& De Georgio-Schoorl, 2016, p. 72). Too easily, we forget our "morethan-human matrix of sensations and sensibilities" (Abram, 1997, p. 22). Still, the inner will to act upon our own environments has managed to persist in some of us. Similarly, some horses have managed to resist human interests and intentions (Armstrong \& Simmons, 2007), and they have maintained their curiosity and will to learn through embodied actions. Cognitively healthy horses do not simply act by instinct; they are intrigued to learn simply because gathering information is interesting (De Georgio \& De Georgio-Schoorl, 2016). "Horses are born cognitive. Their cognitive abilities allow them to understand themselves, their initiatives, each other, their environment, and their social context" (De Georgio \& De Georgio-Schoorl, 2016, p. 12). However, to allow a young animal to maintain its curiosity 
and will to make its own choices, we have to create room for him "to be the protagonist in his own learning experience" (De Georgio \& De Georgio-Schoorl, 2016, p. 60). The same can be said about children or students of any age. Learning through embodied actions provides opportunities for being an opportunist in one's own learning because it demands engagement from the first-person perspective (Stelter, 2008), requires constant choices of action and calls for taking responsibility for the action (see Figure 1).

\section{Methodological framing Methodology}

With the aim of understanding the phenomenon of embodied learning in a holistic way, disregarding traditional divisions between species, I use an untraditional method of complementing data from different species. An in-depth understanding of a phenomenon demands a qualitative approach (Stake, 2010). An arts-based approach implies a qualitative methodology that seeks to gain a holistic understanding of a phenomenon. However, only recently have arts-based studies begun to include more-than-human perspectives (see Bastian et al., 2017; Fawcett \& Johnson, 2019; Hagström, 2018). Arts-based researchers apply their emotions, senses and creativity to investigate issues that are often invisible (Barone \& Eisner, 2006). These approaches have the capacity to challenge taken-for-granted assumptions and address questions of power, inequity and unfairness (Flick, 2017). By questioning the inequity between embodied and verbal forms of learning, and between humans and more-than-human beings, this article suggests that a justification of embodied learning as crucial for survival across species could raise the status of embodied learning in the contexts of education.

The phenomenon of embodied learning deserves a methodological approach that prioritises embodied forms of understanding. Arts-based researchers practice empathetic connections with those engaged in their studies; they place themselves in the shoes of others in order to understand them through their own embodied experiences (Bresler, 2006a). Furthermore, arts-based researchers use narrative, artistic or poetic forms of research dissemination in order to initiate an embodied, empathetic understanding of their audience. This approach was adopted in my doctoral study with young children (see Fredriksen, 2011a), from which half of the empirical examples in this article are drawn. The other half comes from a more recent study with a foal, where the arts-based approach has been enriched and expanded by post-human ontology.

Post-humanism is an ontological position that facilitates the contexts for holistic knowledge production. Similar to new materialism, where contributions from the physical environment are acknowledged in knowledge production, post-human perspectives expand possibilities for the inclusion of more-thanhuman subjects in research. According to Spannring (2017) post-humanism:

\footnotetext{
...does not proclaim the end of humanism, but questions the ontological and epistemological assumptions underlying the notion of 'human nature', [and] draws attention to the myriad ways in which animals are always already part of ourselves, our learning and our culture. (p. 65)
}

To understand others, "we use our personal experiences of what it is like to be a living being" (Rautio, 2017, p. 100). The fact that personal experiences are taken seriously has methodological implications for the choice of research subjects (co-researchers), the performance of the researcher's role, the choices of the approach used and the ethical considerations. Qualitative researchers are expected to be aware of the emerging reality in the specific contexts, to be sensitive to what is significant and to make appropriate ethical judgements according to the ever-changing reality (Eisner, 1991). In this complex reality, one needs to be open-minded to notice when something out-of-the-ordinary occurs. It is exactly when something unexpected happens that new understanding is triggered (Brinkmann, 2014). Grappling to understand what research participants are struggling with can lead to the researcher's own micro-discoveries/new insights. It has been said that the arts have the power to "give us the estranging sensitivity that is necessary to experience a breakdown in understanding" (Brinkmann, 2014, p. 724). Similar to the children's and the foal's micro-discoveries, my own micro-discoveries emerged from 
staying with such puzzling moments. We need to allow ourselves to stay "unbalanced for a moment longer than is comfortable, for this is where we may learn something new" (Brinkmann, 2014, p. 724). Following Brinkmann's (2014, p. 720) advice, my choices of data for this article were driven by "astonishment, mystery and breakdowns in (...) understanding" - the children's, the foal's and my own.

\section{More-than-human research ethics}

In the study conducted with young children, formal approvals were obtained according to Norwegian research regulations, and the children were anonymised. Earlier publications from the study did not even disclose the location in Norway where the data had been collected, and it is impossible to track the data back to the actual children. In contrast, the whereabouts of the foal is not as secret: she is recognisable through her connection to me. It seems absurd to expect formal consent regulations to apply to more-than-human research agents. I could not ask my foal or her mother for consent; however, this impossibility to ask and receive a clear answer made me even more responsible for the foal's wellbeing. Unlike experimental research with animals, the foal was never removed from her natural environments where her mother and I were persistently co-parenting her. During the data construction/collection, the foal was not exposed to elements or conditions that were not natural parts of her environments. Even my presence as a researcher was not extraordinary because I have been present in her life from the moment she was born.

Ontologically creative aspects of research demand greater ethical responsibility than traditional forms of research (Rosiek, 2018). "Multispecies approaches are grounded in the understanding that careful attention to diverse ways of being is inseparable from the work of ethics" (van Dooren et.al, 2016, p. 16). In post-human research, ethical commitment is about ongoing attentiveness and caring for the well-being of all of the agents involved in the research process (Krzywoszynska, 2019). Ethics is about "more-than-cognitive modes of attention" and awareness of mutual interspecies vulnerability (Taylor \& Pacini-Ketchabaw, 2019, p. 51). Taking more-than-human agency seriously is what makes all of the co-researchers both responsible and vulnerable (Taylor \& Pacini-Ketchbaw, 2019). According to Barad (2012):

....agential realism ethics is about responsibility and accountability for the lively relations of becoming (...). Responsibility, then, is a matter of the ability to respond. Listening for the response of the other and an obligation to be responsive to the other, who is not entirely separate from what we call the self. (p. 69)

In this article "the other" refers to the children, the foal, mud, snow, wood and water, and to myself when seen from the perspective of the children and the foal; all of us responded and shaped each other through the ongoing intra-actions, or, as Dewey (2005 [1934]) would have said: through parallel processes of internal and external transformations.

Ethical obligations refer to caring for the participants in a research study; thus, dissemination of the research findings can have ethical and political implications that exceed the concreate research contexts. Promoting the young, more-than-humans' capacities to learn through their own experiences could liberate readers "from the prison of habituated discourse" (Rosiek, 2018, p. 636); this could lead to the empowerment of young more-than-humans, which, in itself, is an ethical goal. By acknowledging more-than-human agency in embodied learning, this article illuminates some aspects of the "marginal worlds of children and animals" and by doing so it seeks multispecies environmental justice (Taylor \& Pacini-Ketchabaw, 2019, p. 6). My hope is that "better worlds [can] result" (Krzywoszynska, 2019, p.663) from my efforts to articulate the speechless and shushed voices of young more-than-humans.

\section{Multispecies ethnography}

Ethnography is a method from social science where people or cultures are studied over an extended period of time. Multispecies ethnography is a hybrid method related to the animal turn, which is appropriate for meeting the increasing interest in understanding the phenomenology of nonhuman animals (Pacini-Ketchabaw et al., 2016). Multispecies ethnography advocates for more nuanced entanglements that link the lived experiences of humans and nonhumans (Haraway, 2008). Research 
that welcomes more-than-human subjects offers a different set of methodological possibilities for studying a phenomenon that are multiple, contextual, subjective and developed through complex relationships (Ulmer, 2017). Studying nonhuman or other-than-human individuals allows for an understanding of their complex lives and unique personalities, as well as the biological abilities that are shared with the researcher. If we want animals to teach us what it means to be human (Bradshaw, 2009), we have to study them with respect to their ways of living.

In the study of my foal's experiential learning, I could not ask her to perform what I needed for my research. I had to be present over an extended period of time and conduct "slow research" in order to capture the phenomena I was studying (Pacini-Ketchabaw et al., 2016). I was fortunate to have the opportunities to stay with her, with Zafirah, as often and as long as I wanted. This made it possible to think with my foal (Ulmer, 2017) - to think with Zafirah (Haraway, 2008) while we both grappled through common environments. I could never know what she was thinking, and why she was acting in the way she did, but our close relationship made it possible for me to understand her through my own body. Such empathetic connections are possible across species since humans and other species have molecular analogies for moods and emotions (Accorsi et al., 2017).

Experiences are co-created with mutual contributions from all of the participants, whether human or nonhuman (Bradshaw, 2010). Daily interactions with Zafirah and her mother, Zvekki, influenced the development of our relationship, trust and confidence; in turn, this allowed for deeper connections. Zvekki showed that she accepted and even expected my co-parenting. Since knowing is intimately connected to doing (Brinkmann, 2014; Sheets-Johnstone, 2011), having the opportunity to simultaneously deal with the same environment, ground and air, rain and sun with Zafirah, made her experiences more accessible. Similarly, in my earlier research where children played with materials, my own play with the materials made it possible to establish better embodied, empathetic connections with the children's experiences. It has been said that even adopting a body posture of another morethan-human being can mediate the content of existing thoughts, feelings and moods (Maranan, 2015). I could, for instance, sense that the clay in my hands was wet, soft and cold. During my interactions with both the children and the foal in the process of data construction/collection, I had the chance to mimic their body language. This was extremely helpful in my later analysis of the video material as well as the narrative analysis. The fact that our experiences were co-created made it possible to sense when the children and the foal experienced surprises and micro-discoveries. This was further important for my choice of the narratives. Thus, it is important to note that my co-researchers were unable to participate in the creation of the narratives. After all, narratives constructed from data always represent a researcher's virtual reality (Bresler, 2006b). My creation of the narratives for this article was influenced by my subjectivities, personal engagement with the children and the foal, and my specific interest in embodied learning. Qualitative researchers are expected to be aware of their own subjectivities and connoisseur skills that inevitably colour every step of the research process, including the construction of narratives (Eisner, 1991).

\section{Selection of the narratives}

Although a few stories cannot produce hard evidence, even a single story can help us understand something (Denzin, 2017). Increasing value has been "placed on stories of experience as research data" (Asfeldt \& Beames, 2017, p. 80). For this article, I selected parallel narratives from my studies with children and my observations of Zafirah, three from each. Each narrative represents highly contextual events that unfolded in unique conditions and with unique individuals. The narratives targeting the children's experiences come from my doctoral study, which was conducted 2008-2011. That was a multiple case study of nine educational settings using participatory observations and video recordings (see Fredriksen, 2011a). The selection of children and materials was not random; it was tailored to fit the research question (Stake, 2010): How do children negotiate meaning when they play with threedimensional materials? For this article, I have chosen to present the narratives from contexts in which the children played with snow, water and wood.

My observations of the foal, Zafirah, started from the time she was born, 4:20 AM on 20 June 2018 (Figure 2). Having known the foal's mother, Zvekki, for many years, I hoped that Zafirah would 
inherit some of her mother's characteristics: curiosity, creativity and a persistent will to act (see Fredriksen, 2019b). The moment Zafirah was born, her resemblance to her mother's personality was obvious: she tried to stand up even before her hind legs were out of her mother's womb and she cantered when she was only 40-minutes-old. Zafirah's explorative attitude made her an excellent candidate for the study of embodied learning. I was spending 2-5 hours with her every day; thus, I had the opportunity to document some of her first experiences. The narratives chosen for this article describe her experiences with mud, water and wood during the first 10 days of her life, 20 June to 30 June 2018.

In the studies with children, the entire educational contexts were filmed. However, in Zafirah's case, I could never know when something of interest would occur. I had my camera with me, and I sometimes managed to capture events of interest. The events that were not filmed were written as narratives immediately after they had occurred. Zafirah's play with water is captured on video.

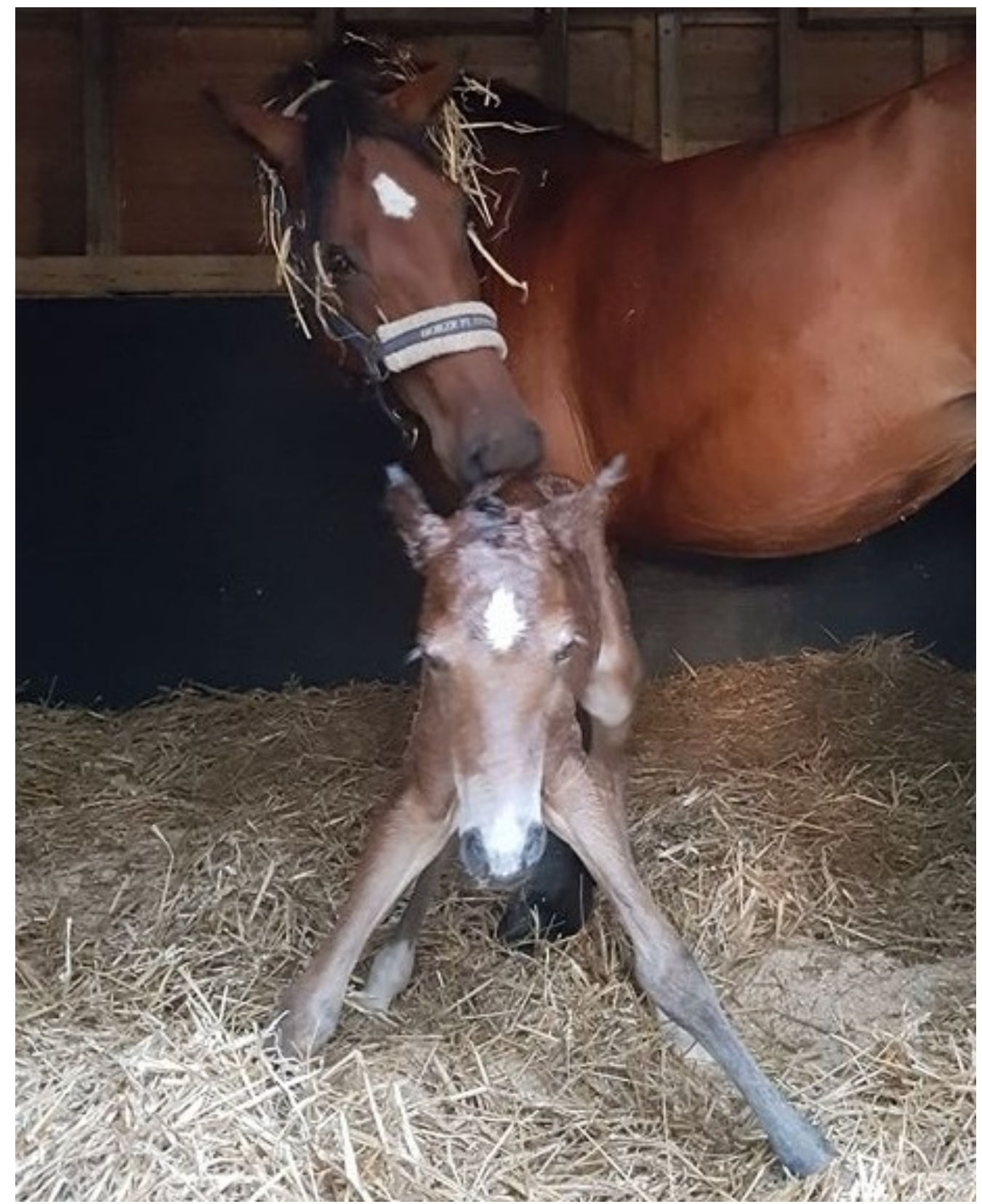

FIGURE 2. Zafirah standing for the first time. 


\section{THE NARRATIVES}

Narratives from the children's material explorations are coupled with narratives from Zafirah's material explorations. The first two narratives are about the embodied experience of moving across a surface. The second pair of narratives focuses on the theme of water explorations. The main theme of the fifth and sixth narratives is the experience of being frightened by a piece of wood. The narratives are analysed in pairs.

\section{The surprising surface of snow}

Three children, aged 3-5, were playing together on a pile of snow that had been made by a snowblower prior to their arrival. They were crawling up the slope following one another without talking but barking like dogs. When the two boys in the front disappeared over the top, the girl at the back, Lea, was not eager to reach them. She seemed occupied by her own movements and continued playing by herself. Based on the sounds she was making, I got the impression that she was relaxed and enjoying herself. After some time, Lea slowly and carefully stood up from the crawling position, and she seemed surprised that her feet did not sink through the surface of the snow. The snow resisted her weighed and supported the soles of her boots. She cautiously started to move her feet. Sometimes, she pushed her feet forward and some snow gathered around the tips of her boots. Other times, she lifted her feet and stamped them in the snow applying pressure. She stamped repeatedly, and the snow responded a bit differently every time. When one foot sank all the way to her knee, Lea constrained the muscles in her other leg to save her foot from being swallowed by the snow. However, putting too much weight on the other foot led to it sinking. She lost her balance and fell over, but instead of trying to stand up again, she simply rolled down the slope, pulling her feet out of the snow. When she reached the flat ground (where the snow had been removed) she stood up and again crawled up to the top of the pile of snow, and continued her explorations. Her movements were accompanied by grunts, cheers and other non-verbal expressions of surprise, joy, dissatisfaction or struggle.

I was standing with my camera about 10 metres away. My presence did not seem to disturb her. She seemed to be 'in her own world', but conscious of me watching her. From her short glances at me and the exaggerated sounds she was making, I got the impression that she wanted me to see her, to respond or to simply acknowledge her play. I stood there for 6 minutes before she passed me and joined the other children.

\section{Mysterious scars}

Zafirah was born in a little stable with direct access to the outdoor environment. During the first hours of her life, she had already tested the three horse paces (walk, trot and canter). Her mother did not allow her to lay down, and she practiced moving around her mother. She seemed to learn how to move on the soft straw of her 'nursery'. When she was 15-hours-old, she took her first steps into the outdoor environment; she lifted her hooves high as if she was still walking on the straw, but she soon discovered that the outdoor ground was hard. The soil was also dry, but she could not know what "dry" meant.

On the second day of her life, I observed Zafirah falling down to the ground in one quick movement, and then, a few seconds later jumping up straight into a gallop. I first thought that something was wrong, but she kept doing it over and over again. I soon realised that she was training a kind of 'jump and run', possibly a skill she would need in the wild. I also realised that her mother now let her lie down to sleep but woke her up and pushed her to stand if someone approached them. By the fifth day, Zafirah was already an experienced runner with the ability to make precise circles around trees, abrupt stops and jumps over roots and stones. Her control of her legs increased more every day, and she could gallop really fast.

The summer of 2018 was extremely dry with only a few, brief showers, one of them during the sixth night of Zafirah's life. When Zafirah ran out of her stable the morning after the shower and made her spectacular abrupt stop in the middle of the enclosure, she kept moving for another metre. She was on her way to meet me, and I could clearly see her reaction and expressions from where I was standing, three metres away. She seemed surprised, not in a scared way, but more confused. Her front hooves had slid forward and to each side of her body, the right a bit more than the left, but she did not lose her 
balance. She froze. She stood still for a few seconds, looking at her legs and the mysterious two lines on the ground. The stripes were connected to her hooves and disappeared somewhere under her body. She quickly gazed at me and ran back to her mother (who was eating breakfast) only to come back towards me again. Again, she tried to stop, and the soggy ground played with her. This time, she literally watched her hooves slide, cutting the soft ground and leaving two scars on it. When her hooves stopped moving, she watched for another three seconds to make sure that they did not move any more by themselves. In her third gallop around the enclosure, she did not stop; she kept going in a circle over the slippery surface. Her body was pulled by the centrifugal force and she almost lost her balance, but she did not stop. She kept running in circles, sliding but still galloping. I was anxiously holding my breath and hoping that she would not hurt herself.

\section{A submarine should not float!}

Two boys aged 4 and 5, respectively, were playing with pieces of wood, bits left over from a carpentry workshop. Among the plank pieces of different shapes and sizes, they found some shapes that reminded them of boats, so they started to construct small boats. While they were building their vessels, I helped them by holding the pieces they were assembling, by finding appropriate nails, and the like. When one of the boys, Alexander, finished making his boat, he had the idea of building a submarine. As the construction of the submarine progressed, we talked about boats and submarines. I was wondering about the differences between those two vessels, and he responded: "Oh, submarines move under water, you know!" I asked him to show me and we fetched a bucket of water. Alexander tied his submarine to the boat, imagining that the boat would pull the submarine out of the water. He placed the boat and submarine in the bucket, and he was very surprised and disappointed when the submarine did not sink under the surface of the water: "Oooooh, it is not supposed to float!" This surprise motivated both of the boys to test which objects and materials could sink. Engaging in interesting conversations, the boys tested what they had available: different sized pieces of wood, nails, paper, pieces of plastic and Styrofoam and a hammer.

\section{Catch and drink}

When she was eight-days-old, Zafirah and her mother were moved to a pasture for a few hours. After some running around, Zafirah explored the bathtub that was filled with water for horses to drink. Some other horses had been drinking there earlier, and small pieces of grass were floating on the water's surface. Zafirah seemed to find this amusing; she started to catch the blades of grass in her mouth. She targeted each of them from about 10 centimetres above the water's surface and quickly snapped her mouth. Sometimes she snapped before her lips met the surface of the water. Other times, she managed to touch the water but did not manage to catch the grass. A few times, she aimed too low and caught a lot of water. The water splashed around her head, and she closed her eyes to avoid the drops, but she kept splashing.

She kept playing with the water and exploring her own precision in moving her mouth and head in relation to this exciting element. After a few minutes, she seemed to have given up grasping for the grass blades and was pleased with just catching the water (Figure 3). From the movements in her throat, I could see that she had swallowed some of the water. She seemed to like the taste and continued catching the water instead of sucking it up as horses usually do when they drink. Indeed, this was the first time I had seen her drink water. Until that point, she had only been drinking milk from her mother. Today, a year later, she still drinks water in her unique way by splashing and catching it. 


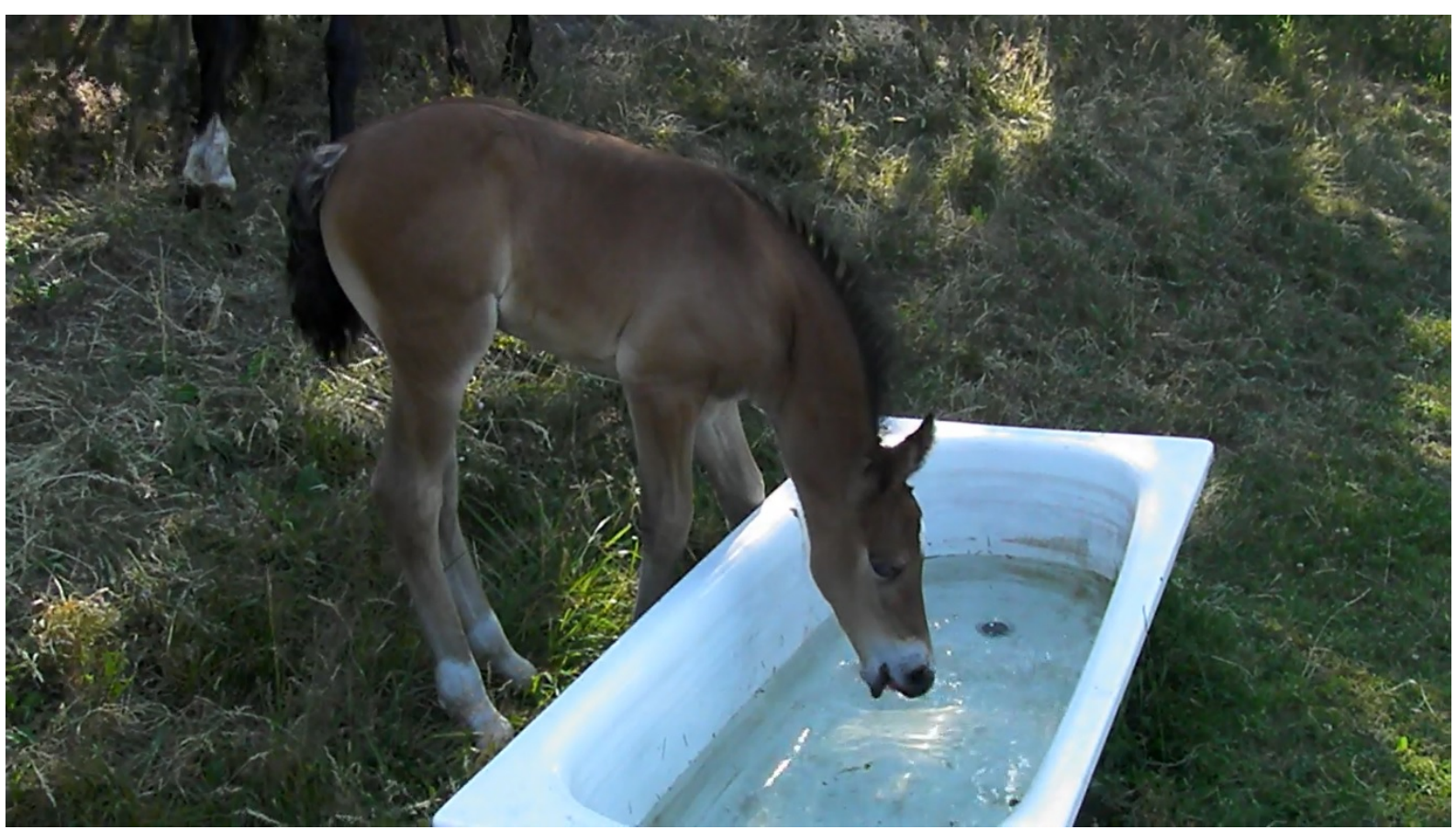

FIGURE 3. Zafirah catching water.

\section{A log that shouts}

To facilitate inspiring play space for two 3-year-old boys, Morten and Emil, a bicycle shelter was turned into a woodshed and arranged in order to remind them of the room where Emil from Lönneberga1 played in Astrid Lindgren's books. A number of small hand-carved sculptures, tools and appropriate materials were placed on the shelves. I had collected fresh juniper branches and mossy roots with mysterious shapes and placed them in the middle of the room. A video camera on a tripod had been placed in a corner prior to the boys' arrival.

When the boys entered the room, they found many things to do. They pulled the branches, tied and taped them, rolled them and walked them like dogs on leads. They saw possibilities in each of the objects, tools and materials. To direct their attention to the wood, I closely explored some of the wood pieces. One of them was a large piece of bark with round holes. Emil lifted it up and used it as a mask. He changed his voice when he spoke through the mask. To imply that it was possible to transform the wood, I picked up a small sculpture from the shelf. "Maybe it was Emil from Lønneberga who made these sculptures?" I asked with my eyes and mouth open, trying to act surprised. "Maybe Emil will come here and wonder what we have been doing?" Morten laughed.

I was squatting beside Emil, smiling at him and talking to Morten, but then I realised that Emil was strangely silent. I touched his hand, smiled at him and asked: "What do you think Emil?" While Morten was trying to get my attention, I saw how Emil slowly bent his head and looked at the ground. He seemed scared. While Morten continued to speak and walk around, Emil stood still and said in a low voice: "I want to go!" I could hear him breathing and his very low voice repeating: "I want to go to my mummy!" While we were preparing to leave the room, Emil picked up a specific piece of wood with a large round shape, a mark from a missing branch: "Make the daddy! Emil's daddy!... Make the mouth that shouts... Daddy shouts: Emiiiiiil!"

That was when I understood that "my" Emil was scared when he thought about Emil from the book and his angry father.

\section{Dangerous branches}

During the unusually hot summer, there was not much fresh grass in the pastures. I collected some fresh branches to feed the horses and used the green pasture only occasionally. Some trees at the edge of the pasture had dried out and died. The pasture was fenced by a few lines of white electric wire, and in 
the corner of the pasture, close to the trees, a bump in the ground made the wire's distance from the ground much higher than in other places. The fence was still high enough for the adult horses, but Zafirah discovered that she could run under the wire, and she found it very amusing. She only had to lower her head: "Swish" and she was on the other side. She did the same procedure on the way back. This particular day, the tenth day of Zafirah's life, the electricity was not connected to the fence and she had found that out. I was not afraid that she would run away, but I did not want her to get used to running under fences, so I grabbed a dry branch laying on the ground and placed it in a way that it restricted her escape. She was ready for another run, when she noticed the obstacle and approached it curiously. I knew that she had been in contact with branches before, but she seemed to approach this branch as if it was something else. She was cautious in her movements toward the branch. I was standing by the branch, and I touched it with intention to show Zafirah that it was "only a branch!", but that made her take a quick 180-degree turn away from the branch. Her rear legs were charged and ready to kick the branch. I was surprised and a bit nervous since she could have kicked me, too. Then, I tried to understand what could have scared her. I tried to attune to the way she was sensing and be attentive to her attention. Then, I realised that the dry leaves were dark and stiff. Their outlines were sharper and more jagged-edged than the outlines of fresh, green leaves. Of course, my shaking of the branch must have made an unfamiliar sound for Zafirah. It was the rattling sound that made her jump away and get ready to protect herself.

I was waiting for her to approach the branch again, which she did that after a few seconds. She needed to explore the branch at her own pace: smell, touch it carefully with her muzzle, nibble it a bit, taste it and paw it with her hoof. Then, she grabbed it with her teeth and pulled it while backing up. When the branch tried to catch her, she again jumped and turned in the air, and warned the branch with her hind legs.

\section{DISCUSSION OF EMBODIED FORMS OF LEARNING \\ Embodied experience of surfaces}

At first glance, a child's frolicking on snow and a foal's prancing after rain do not seem to be special events; however, I suggest that Lea's and Zafirah's experiences were special to them. Considering that snow is a frequent element in Lea's environment, I suppose that she had already, during the four years of her life, acquired experiences with the diverse qualities of snow. Still, she seemed surprised when the snow did not sink under her feet but firmly supported her weight. Did she think that snow was always soft? The surprise was a result of dissonance between what she had experienced earlier and what happened in this new context. It was exactly the combination of what was known and what was still unknown that provoked her thought (Dewey, 2009 [1909]) and motivated her explorations.

A child's exploration of a material leads to both generalisation and differentiation (Smith, 1982). Lea's general understanding that snow is soft (a generalisation) was confronted by the specific qualities of the snow on that particular day (a differentiation). Since action and perception are tied together (Gibson, 1979), her perception of the snow developed as she was exploring it. It was through motoric actions that Lea could become acquainted with the specific snow quality because motor, perceptual and cognitive capacities all depend on the physical body (Fugate et al., 2019). While she was exploring the possibilities of the snow, she was also exploring the possibilities of her own body and the relationship between herself and the material element. As she was actively exploring these relationships, she also seemed to be "moving through several different conceptual states of mind, from the intense sensory experience to critical reflections" (Gulliksen, 2016, p. 2)

At first, Lea followed the boys and copied their movements. However, when she decided to stop following them, she seemed to enter another mode of play; her actions then seemed to be driven from the inside, by her inner will to act upon her environment (Merleau-Ponty, 1962). The moment of surprise, when she did not sink through the snow, was a moment of micro-discovery that seemed to generate further motivation for action.

Similarly, Zafirah's explorative actions were motivated by the surprising response from the ground upon which she was moving. The slippery ground played with her hooves. She did not know why 
and how, and will never be able to understand in terms of verbal language but her repetitive exploration with nuanced changes of action show that she was learning about the ground and her hooves, but most of all about the relationship between her and her environment. She was attuning her body to the surfaces she was experiencing for the first time. To learn from her first-hand experiences, she tried again and again until she could respond to the ground in an appropriate way without risk of injury. For a horse, a broken leg can mean the end of the potential to survive. Such fragility demands extreme attention to details in order to prevent injuries. I could sense how attentive Zafirah was during her runs and stops; I could see what she was seeing and hear what she was hearing, but her private tactile, olfactory and kinaesthetic senses were certainly also involved in her holistic experiences where she intra-acted with the mud (Lenz Taguchi et al., 2010) and grappled to understand (Haraway, 2003).

Through the intimate conversation with the wet soil, Zafirah could get to know her own body from the inside. Through their somaesthetic encounter with surfaces that supported their bodies (Shusterman, 2008) both Lea and Zafirah could sense how their actions were related to their breathing, pulse, muscle contractions, balance, weight changes, friction, centrifugal force and other forces of nature. At the same time, it was their choice of actions (the type of movements, speed, direction, angle of legs and so on) that affected the materials they intra-acted with. Nevertheless, the snow and the soil were not completely inanimate. The snow was tricky, sometimes firm, sometimes soft; the soil was sometimes sticky and did not let go of Zafirah's hooves, and other times it impatiently pushed her hooves away. Materials can have their preferences and even a sense of humour (Pacini-Ketchabaw et al., 2017). Neither of the two materials was ready to forgive, but bravely carried the scars.

In both instances, dealing with the unpredictability of snow and mud were potentially risky, and risk can be the driving force behind curiosity and the motivation to explore (Dewey, 1916). While the risks to Lea and Zafirah were not great, they still facilitated a playful space where it was possible to achieve mastery. This mastery was particularly possible because there was something to struggle with; learning is made possible when there are challenges to be overcome (Eisner, 2002).

Natural materials call for continual dialogue, because they are always a bit different, always unique and a bit challenging. Unlike fabricated play materials that "minimalize risks, restrict initiative and reduce judgement to a minimum" (Dewey, 1916, p. 231), natural materials invite the entangling necessary to become part of the world (Haraway, 2003) through nonverbal, unconscious and implicit forms of becoming (Bradshaw, 2010).

\section{New experiences with water}

Alexander, his friend and Zafirah were all learning about water through embodied interactions with it. Their explorations started with purposeful actions, but gradually developed into more explorative play where small objects were manipulated in relation to the water. Alexander's hand motions in manipulating pieces of wood in the bucket of water were equivalent to Zafirah's use of her muzzle and lips to manipulate blades of grass on the water's surface.

Hands are important instruments for humans. In evolutionary perspectives, development of the human hand has led to the development of the human brain. Transformation of materials in hands exhort inner transformations of thoughts, emotions and understandings (Dewey, 2005 [1934]). While Alexander and his friend explored the relationships between diverse materials and water, they were developing their embodied understanding about the affordances of water and other materials. They were testing what they had imagined prior to their actions. Thus, what Alexander could imagine about his wooden submarine depended on his past experiences and already established understandings. Cognition is closely connected to imagination (Efland, 2002) and imagination has its origins in embodied, perceptual experiences from the past (Efland, 2004). In Alexander's case, when he discovered a dissonance between what he imagined would happen and the concreate actions water and wood performed in front of him, he could realise that his understanding needed to be re-created (Dewey, 2005 [1934]).

Alexander's realisation that he could not know in advance which objects were able to float, was, in itself, an important achievement. Finding out that he had to test in order to see was an act of thinking 
about thinking - a metacognitive act. By becoming aware of his own role in the exploring activity and what he was learning from it, Alexander was also learning what it means to learn (Fredriksen, 2016a).

One could say that the boys' explorations were a kind of science project that could support their learning about mass, weight, water pressure, material density and the force of gravity. Their play was interdisciplinary, and it could lead to different kinds of knowledge. The action-driven embodied learning initiated by the boys' own will had the capacity to motivate their further actions. Experiences motivate more experiencing (Eckhoff, 2008), and such innocent play with water could further motivate the boys to, for example, ask questions about different animals' abilities to live under the water's surface. In Zafirah's case, her stage for play was the water's surface. The objects she was playing with were floating. However, her actions were not explorations of the relationship between the water and the gras; rather, they were explorations of nuances in the actions that involved her mouth, lips, tongue and teeth. Nevertheless, her playing with grass led to the discovery of how to drink water. As mentioned above, her first experience of drinking water led to her unique, personal manner of drinking further on in her life. Zafirah could not share with me her thinking in action; she was thinking with her body and acting accordingly with her lips, as "movement of organisms is fundamentally commensurate with their essentially tactile, proprioceptive, and/or kinaesthetic sensitivities" (Sheets-Johnston, 2011)

During the seven years of my companionship with Zvekki first, and Zafirah more recently, I have come to understand what delicate and sophisticated instruments horse muzzles are in manipulating all kinds of objects. While muzzles cannot transform materials in the same way as human hands can, muzzles and front teeth can grip small shirt buttons and open zippers and Velcro straps. Zafirah's explorative use of her muzzle has been fascinating, especially when combined with her desire for making sounds on string-like objects, such as a dung fork.

Through material manipulations one gets to practice one's ability to attune to different environments. Further contemplation on Dewey's notion of parallel outer and inner transformations leads one to the conclusion that nuanced hand/muzzle activities demand delicate attention; at the same time, attention to details leads to differentiation in understanding. Once again, action and perception are tied together (Gibson, 1979; Sheets-Johnstone, 2011) and exploring materials leads to differentiation and deeper understanding (Smith, 1982). When in dialogue with materials, one can immediately experience the materials' responses and adjust one's own actions appropriately. "We make concessions to the material and we make compromises with ourselves, due to the will of the material" (Groth et al., 2013, p. 8). An embodied dialogue with environments is complex, immediate and risky. Both a child and a foal need to learn how to deal with the physical, practical, cognitive and emotional affordances of their own bodies, and they have to take responsibility for their own actions. Manipulating something concrete in one's hands (or muzzle) challenges abstract thinking (Sheets-Johnstone, 2011). Since materials are tangible, they support the ability to organise experiences, emotions and imagination (Smith, 1982).

\section{Scary wood}

The exploration of materials with a variety of qualities provides settings for the development of aesthetic attention and for expression (Eisner, 2002). When children play with materials, they pay attention to the materials' affordances and they create what they need in order to process their experiences. However, what they wonder about and how they feel also has an impact on how their attention is directed and what they might notice and be inspired by. When Emil observed the specific shape encompassed in a log, it reminded him of Emil's scary father in Lindgren's book (or the movie). Or was it the opposite way around? His fear was perhaps there first, and it made him notice the shape? When Emil suggested what we could make from the log, he expressed metaphorically. He did not say: "I am afraid". Instead, he pointed at the round mark in the log and insinuated that it reminded him of a screaming mouth. At that point, his past and present experiences merged in a micro-discovery and his troubling embodied thoughts got translated into a creative idea. Emil's connection between his past experiences from reading and looking at the pictures of Lindgren's book (or watching the movie) and some side of the new experience led to a creative solution that seemed to help him overcome the fear. 
Emotional engagement is akin to knowing from the inside (Ingold, 2013a). Fear is a serious emotion, embodied and difficult to ignore. When Emil got scared, I was struggling to understand what happened; at the same time, I feared that I had done something unethical. My breakdown in understanding (Brinkmann, 2014) demanded that I attune to Emil, so I could try to understand him and find out which actions would be ethical and appropriate to take. Emil did not express his fear verbally, but I sensed it inter-subjectively (Stern, 2003). I could not know what he was thinking, and he was probably not aware of that himself until an affordance of a log made it possible for him to express it. His thinking was embodied (Parsons, 2007). Children's somatic experiences, embodied thoughts, memories, fantasies and feelings often find their way to expression through metaphoric stories (Fredriksen, 2011a). Emil's utterance - "Emil's father shouts: Emiiil!" - seemed to be a glimpse of an unspoken story. It pointed to his past experiences and identified the source of his fear.

In Zafirah's case, as she approached the branch, she seemed to notice the specific shape and colour of the leaves. She was attentive to the details. She could probably smell and hear the branch and observe how it moved with the breeze. When something seemed unfamiliar, she was prepared to defend herself. The emotions initiated actions that were required to protect herself (De Waal, 2019). It is remarkable how a new-born foal can walk, make her own decisions and even protect herself, from the first hours of life. Imagine how risky it would be if new-born children were able to run before having acquired some basic understandings of the world. Having to take responsibility for her own actions, Zafirah's survival depended on being able to learn fast. Horses often learn from one trial run. Put differently, they do not forget negative experiences, as emotions encourage behaviour that supports survival (Keim, 2017). Emotions orchestrate behaviour (De Waal, 2019). I suppose that Zafirah's attention to details is a characteristic of her genetic make-up. For a horse, differences between a dog and a wolf, or between a nutritious and poisonous plant, are the difference between life and death. If humans are artful by nature (Dissanayake, 2001), horses must be too.

While Zafirah was attentively observing the dry branch, she was making connections between the specific qualities of that branch and branches she had experienced before. She must have been thinking in some way, because what she perceived was directly linked to her decisions about how to respond. It took me some time to realise that this particular branch was different from those she had experienced before. She noticed that much earlier than I did; it was her cautious approach that made me focus my attention. She was immediately afraid when she noticed that the branch looked strange, but she was still curious, as mentally healthy horses are (De Georgio \& De Georgio-Schoorl, 2016).

Each of us has our own personal way of experiencing environments (Eisner, 2002); I realised that I might have spoilt Zafirah's slow acquaintance with the branch when I started touching it myself. Zafirah needed more time, and I rushed her. Time for dwelling is essential in order to notice details, and she was more present in the moment than I was. Zafirah needed to communicate with her environment at her own pace, and I was not attuned to her pace. One might say that my influence on the intra-actions between Zafirah, the branch and myself was ethically challenging or even questionable because pushing a horse to learn too fast is an easy way to produce problematic behaviour in them (De Georgio \& De Georgio-Schoorl, 2016). Similarly, was it my fault that Emil got scared? Zafirah and Emil were vulnerable back then-I am vulnerable now when I realise that I should have made different choices. However, back then, as the events unfolded and challenged my responses, I did not know better. I was not neutral. From Zafirah's and Emil's points of view, the objects in their environments were not neutral either, but "battled" for their attention (Abram, 2007, p. 1137) and had their own agendas (Lenz Taguchi et al., 2009). The dry branch prepared to jump on Zafirah, and the log had already opened its mouth ready to scream at Emil with all its force. Our inter-actions are messy and unpredictable, but they shape us in the process of mutual becoming.

\section{EMBODIMENT FOR THE FUTURE}

This article has addressed embodied learning across species' boundaries, implying that embodied capacities, necessary for maintaining flexibility and responsiveness to the changing environments, are present in both young humans and horses. Embodied, evolutionary-developed capacities for learning 
through intra-action with environments are presented as vivid and intact in these young individuals. However, the article also suggests that non-verbal, embodied forms of learning are often ignored in human cultures, and they might be better safeguarded in other-than-human creatures. The established dualisms of the anthropocentric world work against acknowledgment of embodied learning and respectful treatment of other-than-human species. As Bastian (2017, p. 33) noted: "The beliefs that nonhuman could (...) have a stake in broader knowledge making processes, not only challenges political and social contexts but also many of the fundamental assumptions of Western ontological and epistemological frames". When our planet in so many ways depends on human behaviour, we not only can, but must question the values embedded in our cultures and education.

Embodied interactions with natural materials and more-than-human creatures can facilitate a more holistic understanding of the world. We can be amazed by the diversity and wonder of nature-I continue to be amazed by Zafirah. It is through the direct embodied contact with more-than-humans that companionship, empathy and compassion can develop; compassion across species is essential for transforming values and developing ecological responsibility (Bekoff, 2013). Embodied and holistic forms of learning can lead to the development of ecological awareness and the appreciation of the animal capacities in ourselves, as well as the appreciation of animals in their own right. By nourishing more-than-humans, we also nourish ourselves, for we are inseparably connected.

Genuine learning-learning that has the power to transform values-comes from experience (Dewey, 2007 [1938]) and the active engagement of the body (Sheets-Johnstone, 2011). However, it is not without cost: it demands investing time and effort in exploring, dwelling and engaging. Learning through first-hand-experiences teaches us that one has to take the initiative and be responsible for one's own learning (Fredriksen, 2016a). It also teaches us that one has to be attentive to emerging challenges and remain metacognitively active, since metacognition is essential for dealing with uncertainties (Keim, 2017). Young individuals know with their bodies. We adults will have to re-learn how to become more flexible, attentive and ecologically responsible. Aesthetic attention provides us with fresh perspectives, "so that our old habits of mind do not dominate our reactions" (Eisner, 2008, p. 11). Through the arts we can realise that attentiveness to the present contexts matters, and that the process itself is the purpose of life (Dissanayake, 2000).

While we, entangled in our cultural webs, unknowingly train ourselves to ignore our embodied thinking (De Georgio \& De Georgio-Schoorl, 2016), we also prevent ourselves from being fully alive, attentive and creative in the process of becoming. In this way, we are becoming blind to the signs in water and soil that the Earth communicates through. We can pretend to be unaffected by animal suffering, but "turning an ear to animals is an opportunity to re-craft life on this earth" (Bradshaw, 2010, p. 410). Starting to listen, see, touch and be touched is a good start. Empowering people "to feel that they are able to make changes which really matter" (Konst, 2019, not paginated) is not an easy job for any teacher or researcher. However, we must try as hard as we can. What other options do we have? My efforts to promote embodied learning as essential for survival across species might be a tiny contribution, but it feels meaningful to me, and, hopefully, it matters for the health and welfare of our fellow animals and the future of our planet. 


\section{REFERENCES}

Abram, D. (1997). The spell of the sensuous: Perception and language in a more-than-human world. Vintage Books.

Abram, D. (2007). Astonished by a stone: Art and eloquence of matter. In L. Bresler (Ed.), International handbook of research in arts education (pp. 1137-1142). Springer.

Accorsi, P., Mondo, E., \& Cocchi, M. (2017). Did you know that your animals have consciousness? Journal of Integrative Neuroscience, 16(s1), 3-11. https://doi.org/10.3233/JIN-170061

Armstrong, P., \& Simmons, L. (2007). Bestiary: An introduction. In L. Simmons \& P. Armstrong (Eds.), Knowing animals (pp. 3-23). Brill.

Asfeldt, M., \& Beames, S. (2017). Trusting the journey: Embracing the unpredictable and difficult to measure nature of wilderness educational expeditions. Journal of Experiential Education, 40(1),72-83. https://doi.org/10.1177/1053825916676101

Barad, K. (2007). Meeting the universe halfway: Quantum physics and the entanglement of matter and meaning. Duke University Press.

Barad, K. (2012). Interview with Karen Barad. In R. Dolphijn \& I. Van Der Tuin (Eds.), New materialism: Interviews \& cartographies (pp. 48-70). Open Humanities Press.

Barone, T., \& Eisner, E. W. (2006). Arts-based educational research. In J. L. Green, G. Camilli, P. B. Elmore, A. Skukauskaite \& E. Grace (Eds.), Handbook of complementary methods in education research (pp. 95109). Lawrence Erlbaum.

Barrett, M. J., Harmin, M., Maracle, B., Petterson, M., Thomson, C., Flowers, M., \& Bors, K. (2017). Shifting relations with the more-than-humans: Six threshold concepts for transformative sustainability learning. Environmental Education Research, 23(1), 131-143. https://doi.org/10.1080/13504622.2015.1121378

Bastian, M. (2017). Towards a more-than-human participatory research. In Bastian, M., Jones, O., Morre, N., \& Roe, E. (Eds.), Participatory research in more-than-human worlds (pp. 19-37). Routledge.

Bastian, M., Jones, O., Morre, N., \& Roe, E. (Eds.). (2017). Participatory research in more-than-human worlds. Routledge.

Bekoff, M. (Ed.) (2013). Ignoring nature no more: The case for compassionate conservation. University of Chicago Press.

Biesta, G. J. J. (2013). The beautiful risk of education. Paradigm Publishing.

Bradshaw, G. (2010). You see me, but do you hear me? The science and sensibility of trans-species dialogue. Feminism \& Psychology, 20(3), 407-419. https://doi.org/10.1177/0959353510368285

Braidotti, R. (2002). Metamorphoses: Towards a materialist theory of becoming. Polity Press.

Braidotti, R. (2013). The posthuman. Polity Press.

Bresler, L. (2006a). Toward connectedness: Aesthetically based research. Studies in Art Education: A Journal of Issues and Research in Art Education, 48(1), 52-69. https://doi.org/10.1080/00393541.2006.11650499

Bresler, L. (2006b). Embodied narrative inquiry: A methodology of connection. Research Studies in Music Education, 27, 21-43. https://doi.org/10.1177/1321103X060270010201

Brinkmann, S. (2014). Doing without data. Qualitative Inquiry, 20(6), 720-725. https://doi.org/10.1177/1077800414530254

Davis, D. L., \& Maurstad, A. (2016). Biosocial encounters and the meaning of horses. In D. L. Davis \& A. Maurstad (Eds.), The meaning of horses: Biosocial encounters (pp.190-202). Routledge.

De Georgio, F., \& De Georgio-Schoorl, J. (2016). Equus lost? How we misunderstand the nature of the horsehuman relationship - plus, brave new ideas for the future. Trafalgar Square Books.

Denzin, N. K. (2017). Critical qualitative inquiry. Qualitative Inquiry, 23(1), 8-16. https://doi.org/10.1177/1077800416681864 
De Waal, F. (2019). Mama's last hug: Animal emotions and what they tell us about ourselves. W. W. Norton \& Company.

Dewey, J. (1916). Democracy and education. The Macmillan Company.

Dewey, J. (2005). Art as experience. Berkley Publishing Group. (Original work published 1934)

Dewey, J. (2007). Experience and education. Amazon Kindle edition. (Original work published 1938)

Dewey, J. (2009). How we think. Amazon Kindle edition. (Original work published 1909)

Dissanayake, E. (2000). Art and intimacy: How the arts began. University of Washington Press.

Dissanayake, E. (2001). Becoming Homo Aestheticus: Sources of aesthetic imagination in mother-infant interactions. SubStance, 30(1), 85-103. https://muse.jhu.edu/article/32278

Eckhoff, A. (2008). Understanding imaginative thinking during childhood: Sociocultural conceptions of creativity and imaginative thought. Early Childhood Education Journal, 36, 179-185. https://doi.org/10.1007/s10643-008-0261-4

Efland, A. D. (2002). Art and cognition: Integrating the visual arts in the curriculum. Teachers College Press.

Efland, A. D. (2004). Emerging visions of art education. In E. W. Eisner \& M. D. Day (Eds.), Handbook of research and policy in art education (pp. 691-700). National Art Education Association/Lawrence Erlbaum Associates.

Eisner, E. W. (1991). The enlightened eye: Qualitative inquiry and the enhancement of educational practice. Macmillan Publishing Company.

Eisner, E. W. (2002). The arts and the creation of mind. Yale University Press.

Eisner, E. W. (2008). Art and knowledge. In G. J. Knowles \& A. L. Cole (Eds.), Handbook of the arts in qualitative research (pp. 312). Sage Publications.

Fawcett, L., \& Johnson, M. (2019). Coexisting entities in multispecies worlds: Arts-based methodologies for decolonial pedagogies. In T. Lloro-Bidart \& V. S. Banschbach (Eds.), Animals in environmental education (pp. 175-193). Springer.

Finley, S. (2012). Ecoaesthetics. Critical arts-based research and environmental advocacy. In N. K. Denzin \& M. D. Giardina (Eds.), Qualitative inquiry and the politics of advocacy (pp. 205-220). Left Coast Press.

Flick, U. (2017). Challenges for a new critical qualitative inquiry: Introduction to the special issue. Qualitative Inquiry, 23(1), 3-7. https://doi.org/10.1177/1077800416655829

Foros, P. B. \& Vetlesen, A. J. (2015). Angsten for oppdragelse: Et samfunnsetisk perspektiv på dannelse. [The fear of upbringing: A social ethical perspective on education]. Universitetsforlaget.

Fox, K. (2008). Rethinking experience: What do we mean by this word "Experience"? Journal of Experiential Education, 31(1), 36-54. https://doi.org/10.1177/105382590803100105

Fredriksen, B. C. (2011a). Negotiating grasp: Embodied experience with three-dimensional materials and the negotiation of meaning in early childhood education. (Doctoral thesis 58, The Oslo School of Architecture and Design). http://hdl.handle.net/11250/93056

Fredriksen, B. C. (2011b). When past and new experiences meet: Negotiating meaning with 3-D materials in early childhood education. FORMakademisk, 4(1), 65-80. https://doi.org/10.7577/formakademisk.128

Fredriksen, B. C. (2016a). Learning to learn: What can be learned from first-hand experience with materials? Conference publication 2016 Design Research Society, Brighton, UK, 27-30 June 2016. https://www.drs2016.org/103

Fredriksen, B. C. (2016b). Attention on the edge: Ability to notice as necessity of learning, teaching and survival. Visual Inquiry: Learning and Teaching Art, 5(1), 105-114. https://doi.org/10.1386/vi.5.1.105_1

Fredriksen, B. C. (2019a). Før sanden renner ut: Barnehagelærerens innsats for $\varnothing$ kologisk bærekraft. [Before the sand runs out: The kindergarten teacher's commitment to ecological sustainability]. Universtitetsforlaget.

Fredriksen, B. C. (2019b). Inter-species pedagogy: What could a horse teach me about teaching. TRACE: Finnish 
Journal for Human-animal Studies 5(Sep.), 4-30. https://doi.org/10.23984/fjhas.78122

Fugate, J. M. B., Macrine, S. L., \& Cipriano, C. (2019). The role of embodied cognition for transforming learning. International Journal of School \& Educational Psychology, 7(4), 274-288. https://doi.org/10.1080/21683603.2018.1443856

Geertz, C. (1993). The interpretation of cultures. Fontana Press.

Gibson, J. J. (1979). The ecological approach to visual perception. Houghton Mifflin.

Groth, C., Mäkelä, M., \& Seitamaa-Hakkarainen, P. (2013). Making sense: What can we learn from experts of tactile knowledge? FORMakademisk, 6(2), 1-12. https://doi.org/10.7577/formakademisk.656

Gulliksen, M. S. (2016). Embodied making, creative cognition and memory: Drawing on neurobiological knowledge of creative cognition and the role of the hippocampus in memory storage and recollection to explore the experience of carving green wood. FORMakademisk, 9(1), 1-19. https://doi.org/10.7577/formakademisk.1487

Hagström, E. (2018). Mellan människa och häst: Djur-blivande i den pedagogiska relationens mellanrum [Between man and horse: Animal-prospective in the space of the educational relationship]. (Doctoral thesis), Luleå Tekniska Universitet, Luleå.

Haraway, D. (2003). The companion species manifesto: Dogs, people, and significant otherness. Prickly Paradigm Press.

Haraway, D. (2008). When species meet. University of Minnesota Press.

Howes, D. (Ed.) (2005). Empire of the senses: The sensual culture reader. Berg.

Ingold, T. (2011). Being alive: Essays om movement, knowledge and description. Routledge.

Ingold, T. (2013a). Making: Anthropology, archeology, art and architecture. Routledge.

Ingold, T. (2013b). Prospect. In T. Ingold \& G. Palsson (Eds.), Biosocial becomings: Integrating social and biological anthropology (pp. 1-21). Cambridge University Press.

Ingold, T., \& Palsson, G. (Eds.). (2013). Biosocial becomings: Integrating social and biological anthropology. Cambridge University Press.

Keim, B. (2017). Inside animal mind: What they think, feel and know (Vol. Special publication). National Geographic.

Konst, T. (2019). Embedding posthumanism in higher education. TRACE: Finnish Journal for Human-animal Studies, 5, https://trace.journal.fi/article/view/77317

Krzywoszynska, A. (2019). Caring for soil life in the Anthropocene: The role of attentiveness in more-than-human ethics. Transactions of the Institute of British Geographers, 44(4), 661-675. https://doi.org/10.1111/tran.12293

Lenz Taguchi, H., Moss, P., \& Dahlberg, G. (2010). Going beyond the theory: Practice divide in early childhood education: Introducing an intra-active pedagogy. Routledge.

Locke, P. (2017). Elephants as persons: affective apprenticeship, and fieldwork with nonhuman informants in Nepal. HAU: Journal of Ethnographic Theory, 7(1), 353-376. https://doi.org/10.14318/hau7.1.024

Maranan, D. S. (2015). Speculative somatics. Technoetic Arts: A Journal of Speculative Research, 13(3), $291-300$. http://doi.org/10.1386/tear.13.3.291_1

Merleau-Ponty, M. (1962). Phenomenology of perception. Routledge \& Kegan Paul.

Pacini-Ketchabaw, V., Kind, S., \& Kocher, L. L. M. (2017). Encounters with materials in early childhood education: Routledge.

Pacini-Ketchabaw, V., Taylor, A., \& Blaise, M. (2016). Decentring the human in multispecies ethnographies. In C. A. Taylor \& C. Hughes (Eds.), Posthuman research practices in education (pp. 149167). Palgrave Macmillan.

Parsons, M. (2007). Art and metaphor, body and mind. In L. Bresler (Ed.), International handbook of research in arts education (pp. 533-542). Springer. 
Raus, R., \& Falkenberg, T. (2014). The journey towards a teacher's ecological self: A case study of a student teacher. Journal of Teacher Education for Sustainability, 16(2), 103-114. https://doi.org/10.2478/jtes-2014-0014

Rautio, P. (2017). Thinking about life and species lines with Pietari and Otto (and garlic bread). TRACE: Finnish Journal for Human-animal Studies, 3, 94-102. https://trace.journal.fi/article/view/63310

Roberts, J. (2008). From experience to neo-experiential education: Variations on a theme. Journal of Experiential Education, 31(1), 19-35. https://doi.org/10.1177/105382590803100104

Robinson, K. (2016). Creative schools: The grassroots revolution that's transforming education. Penguin Books.

Rosiek, J. (2018). Art, agency, and ethics in research: How new materialisms will require and transform arts-based research. In P. Leavy (Ed.), Handbook of arts-based research (pp. 632-648). The Guilford Press.

Seaman, J. (2008). Experience, reflect, critique: The end of the "learning cycle" era. Journal of Experiential Education, 31(1), 3-18. https://doi.org/10.1177/105382590803100103

Shapiro, K., \& DeMello, M. (2010). The state of human-animal studies. Society and Animals, 18, 307-318. : https://doi.org/10.1163/156853010X510807

Sheets-Johnstone, M. (2011). The primacy of movement. John Benjamin.

Shusterman, R. (2008). Body consciousness: A philosophy of mindfulness and somaesthetics. Cambridge University Press.

Sinnes, A., \& Straume, I. S. (2017). Bærekraftig utvikling, tverrfaglighet og dybdelæring: Fra big ideas til store spørsmål. [Sustainable development, interdisciplinarity and in-depth learning: From big ideas to big questions]. Acta Didactica Norge, 11(3), Artikkel 7, 1-22. https://doi.org/10.5617/adno.4698

Smith, N. R. (1982). The visual arts in early childhood education: Development and the creation of meaning. In B.

Spodek (Ed.), Handbook of research in early childhood education (pp. 292-320). Free Press.

Spannring, R. (2017). Animals in environmental education research. Environmental Education Research, 23(1), 63-74. https://doi.org/10.1080/13504622.2016.1188058

Stake, R. (2010). Qualitative research: Studying how things work. Guilford Press.

Stenslie, S. (2010). Virtual touch: A study of the use and experience of touch in artistic, multimodal and computer-based environments. (Doctoral dissertation, The Oslo School of Architecture and Design). http://hdl.handle.net/11250/93049

Stelter, R. (2008). Learning in the light of the first-person approach. In T. Schilhab, M. Juelskjær \& T. Moser (Eds.), Learning bodies (pp. 45-64). Danmarks Pædagogiske Universitetsforlag.

Sterling, S. (2011). Transformative learning and sustainability: Sketching the conceptual ground. Learning and Teaching in Higher Education (5), 17-33. http://dl.icdst.org/pdfs/files/0cd7b8bdb08951af53e5927e86938977.pdf

Stern, D. N. (1998). The interpersonal world of the infant: A view from psychoanalysis and developmental psychology. Karnac.

Stern, D. N. (2003). Spebarnets intersubjective verden [The interpersonal world of the infant] ( $\varnothing$. RandersPehrson, Trans.). Gyldendal Akademisk.

Taylor, A., \& Pacini-Ketchabaw, V. (2019). The common worlds of children and animals: Relational ethics for entangled lives. Routledge Taylor \& Francis Group.

Thelen, E., \& Smith, L. B. (1994). A dynamic systems approach to the development of cognition and action. MIT Press.

Ulmer, J. B. (2017). Posthumanism as research methodology: Inquiry in the Anthropocene International Journal of Qualitative Studies in Education, 30(9), 832-848. https://doi.org/10.1080/09518398.2017.1336806

United Nations. (2013). Global sustainable development report - executive summary: Building the common future we want. http://sustainabledevelopment.un.org/globalsdreport/

van Dooren, T., Kirksey, E., \& Münster, U. (2016). Multispecies studies: Cultivating arts of attentiveness. 
Biljana C. FREDRIKSEN - More-than-human perspectives in understanding embodied learning

Environmental Humanities, 8(1), 1-23. https://doi.org/10.1215/22011919-3527695

Villemain, F. T. (1966). Democracy, education, and art. In E. W. Eisner \& D. W. Ecker (Eds.), Readings in art education (pp. 407-419). Blaisdell Publishing Company.

${ }^{1}$ Astrid Lindgren's books about Emil from Lönneberga have been adapted into movies and are well known to children in Norway. 